\title{
Influence of cortical thickness on the stability of mini-implants with microthreads
}

Giselle Naback Lemes VILANI (a) Antônio Carlos de Oliveira RUELLAS ${ }^{(a)}$

Cláudia Trindade MATTOS(a)

Daniel Jogaib FERNANDES(b)

Carlos Nelson ELIAS(b)

(a) Universidade Federal do Rio de Janeiro UFRJ, School of Dentistry, Department of Orthodontics, Rio de Janeiro, RJ, Brazil.

(b)Instituto Militar de Engenharia - IME, School of Engineering, Department of Materials Science, Rio de Janeiro, RJ, Brazil.

Declaration of Interests: The authors certify that they have no commercial or associative interest that represents a conflict of interest in connection with the manuscript.

\section{Corresponding Author:}

Giselle Naback Lemes Vilani

E-mail:vilani.bhe@gmail.com

DOI: 10.1590/1807-3107BOR-2015.vol29.0023

Submitted: Nov 06, 2013

Accepted for publication: Sep 23, 2014

Last revision: Dec 05, 2014

\begin{abstract}
The objective of this study was to assess the influence of cortical thickness and bone density on the insertion torque of a mini-implant (MI) with microthreads. Mini-implants with lengths of 6 and $8 \mathrm{~mm}$ in the active part were inserted into synthetic bone blocks (polyurethane resin). The density of these blocks was 20 pounds per cubic foot (pcf), simulating bone marrow, and that of blocks 1, 2, and 3-mm-thick blocks was 40 pcf, simulating cortical bone. Blocks with uniform density of 40 pcf were also used to simulate bone areas of greater density. Insertion torque was quantified with a universal testing machine (EMIC). For both MIs, increasing insertion torque was associated with increasing cortical bone thickness. For the same MI length, significant differences were observed among all assessed groups. The insertion torque of the 6-mm-long MI inserted in a 3-mm-thick cortical bone was equivalent to that of the 8-mm-long MI inserted in a 1-mm-thick cortical bone. MIs inserted in bone blocks of greater density presented insertion torque values almost twice as high as those in other groups. The shorter MI, the lower the insertion torque, and the greater the cortical bone thickness, the greater the insertion torque. To minimize fracture risk, the size of MI should be selected according to the insertion site.
\end{abstract}

Keywords: Orthodontic Anchorage Procedures; Materials Testing; Orthodontics.

\section{Introduction}

Obtaining satisfactory clinical results in orthodontic treatment requires adequate mechanical control, which includes anchorage control. This is particularly true in cases where the space obtained after tooth extraction must be used to align or reposition the teeth; in such cases anchorage control becomes fundamental for orthodontic success.

Tooth-supported anchorage resources have the inconvenient consequence of producing collateral effects on the supporting teeth. Extraoral anchorage depends on collaboration with the patient using the appliance, but patients are increasingly unwilling to accept this. Therefore, the use of a stable anchorage unit that is independent of cooperation and has no side effects on adjacent teeth has been studied in recent years ${ }^{1}$ through the use of conventional implants, miniplates, or mini-implants (MIs). ${ }^{2,3,4}$

MIs constitute a more versatile and easy-to-use resource; they have good primary stability but are not completely stationary. ${ }^{2,3}$ MI stability is directly related to the thickness and quality of the cortical bone. 
In general, cortical bone of greater thickness and density provides MIs with better primary stability. ${ }^{5}$ However, depending on these characteristics, cortical bone thickness and density associated with the size of the selected MI may be sufficient to promote the fracture of MIs during their insertion. ${ }^{6}$

The primary stability of an MI is obtained as a result of the mechanical resistance during insertion; ${ }^{7}$ therefore, cortical bone thickness and density are important in the initial stages.

Because of the higher failure rate ( $9 \%-30 \%)$ compared with conventional implants, there have been many studies assessing factors related to the stability of MIs. ${ }^{1,4,8,9,10,11}$ Some studies have assessed cortical bone thickness and bone density because they are important for the stability of MI. 12,13,14 Using microcomputed tomography, Laursen et al. ${ }^{15}$ found that the thickness of the alveolar cortical bone was often $<1.0 \mathrm{~mm}$ buccally and palatally in the maxilla and buccally in the anterior mandible. However, in the posterior mandible, the alveolar cortical bone was thicker than $2.0 \mathrm{~mm}$. Bonequality usually varies according to the site in the arch; however, in the anterior region, bone density is greater than that in the median and posterior regions. ${ }^{16}$ The stability of MIs is greater when cortical bone thickness is $>1 \mathrm{~mm},{ }^{5}$ but is unaffected by bone density when cortical bone thickness is $1 \mathrm{~mm} \cdot{ }^{14}$

Many variables can affect the stability of MIs. The insertion angle, the direction of orthodontic force, and the exposure length of MI can influence bone stress, and consequently the success of the anchorage. A study using finite element analysis concluded that increased exposure lengths resulted in higher bone stresses adjacent to MI on the cortical bone, causing the MI to fail. ${ }^{17}$ Another study in minipig osseous tissue demonstrated that initial stability can be efficiently enhanced by increasing the length of MI. ${ }^{18}$

An alternative way to improve stability is through modification of the surface and shape of the threaded part of MI. The presence of microthreads in the cervical third of the screw increases the contact area between the bone and MI. This makes it possible to distribute the stress more evenly, increasing MI stability. ${ }^{19,20}$ Kwon et al. ${ }^{19}$ did not find significant mechanical and histological differences, in terms of removal torque and bone/implant contact, when comparing implants with and without microthreads. However, Chang et al., ${ }^{20}$ using mechanical and finite element analysis, concluded that modification of MI design can affect mechanical properties, improving primary stability. The authors observed high stresses on the uppermost thread at the neck of MI near the margin of the bone.

This study had two the following objectives: 1) to assess primary stability measured as insertion torque values of MIs with microthreads inserted in synthetic bone blocks having mechanical properties similar to cortical bone of different thicknesses, and homogeneous blocks simulating denser bone; and 2) to derive a mathematical equation that can be used to obtain the possible insertion torque for different cortical bone thicknesses.

\section{Methodology}

This research used Conexao 5 (Conexao Sistemas e Proteses, Arujá, Brasil) Mls that were $1.5 \mathrm{~mm}$ in diameter, 6 and $8 \mathrm{~mm}$ in length, had a transmucosal neck of 2 $\mathrm{mm}$, and had microthreads in the portion close to the transmucosal neck (Figure 1). Torsion mechanical tests were performed to quantify the insertion torque.

Because there was no specific standard for the situation tested in this study, mechanical tests were performed on the basis of ASTM F117 (Standard Test Method for Driving Torque of Medical Bone Screws) and F1622 (Standard Test Method for Measuring the Torsional Properties of Metallic Bone Screws).

Eighty MIs, comprising 2 groups of 40 MIs ( 6 and 8 $\mathrm{mm}$ length) were inserted in laminated biomechanical test blocks (BLTBs). BLTBs are used as an alternative test medium for human cancellous and cortical bone. They are manufactured with a combination of solid rigid polyurethane foam and cellular rigid polyurethane foam. They do not replicate the structure of human bone; however, they provide consistent material with properties in the range of human cancellous bone. The technical standard ASTM F-1839-08 "Standard Specification for Rigid Polyurethane Foam for Use as a Standard Material for Testing Orthopedic Devices and Instruments" describes the specification of rigid unicellular polyurethane foam for use as a standard material for performing mechanical tests utilizing orthopedic devices or instruments. The uniformity and consistent properties of polyurethane foam make it an ideal material for comparative testing of bone MIs. 


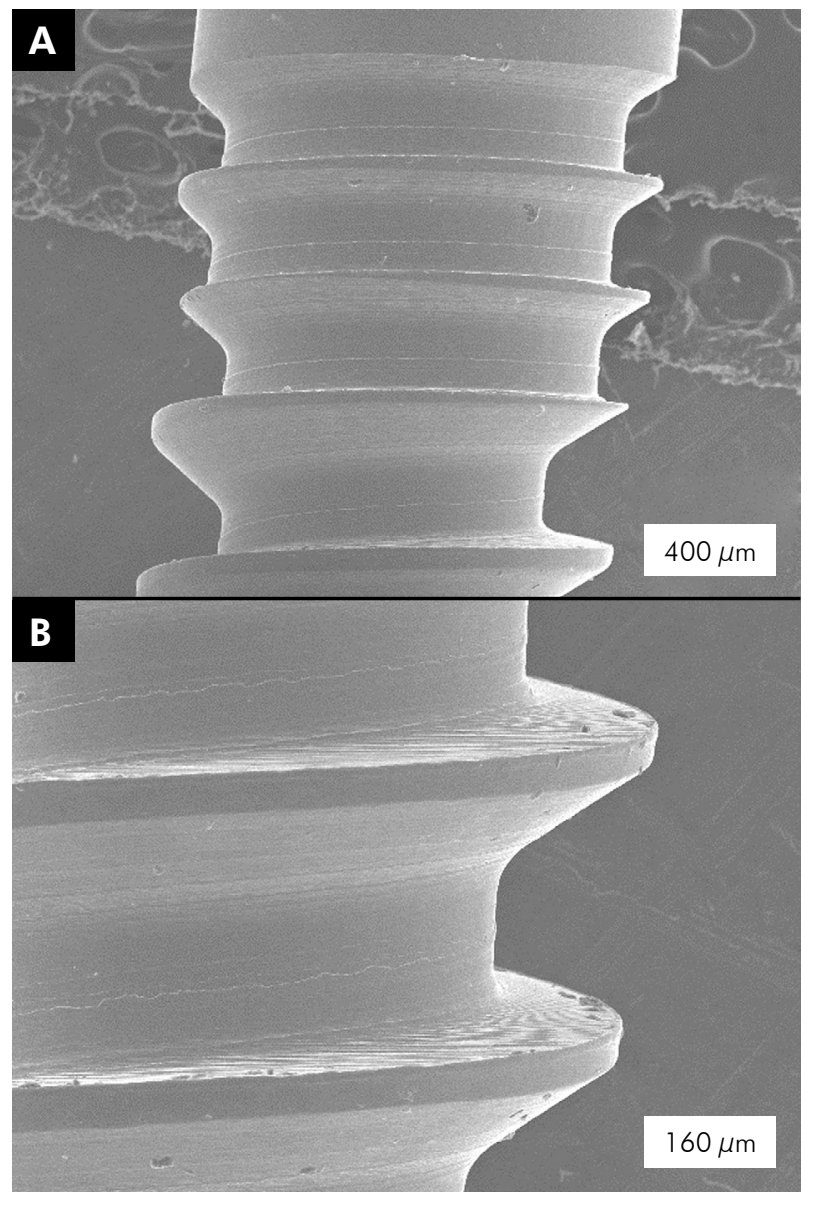

Figure 1. (A) Photomicrograph of retrieved MI, showing it's morphology with microthreads in the portion close to the transmucosal neck. (B) Larger magnification of the microthreads.

The BLTBs used in the present work are available in the Brazilian market and were provided by the Nacional Ossos company (Franceschi e Costa e Silva Ltda. Epp, Jaú, Brasil) (Figure 2). The blocks are made with two resin densities. Their primary use is the simulation of natural bone properties. On the upper part of the blocks, resin of density 40 pounds per cubic foot (pcf) $\left(0.62 \mathrm{~g} / \mathrm{cm}^{3}\right)$ was used in layers of thickness 1.0, 2.0, and $3.0 \mathrm{~mm}$. Resin of density 20 pcf $\left(0.32 \mathrm{~g} / \mathrm{cm}^{3}\right)$ was used in the lower portion of the blocks to simulate bone marrow (Figure 2). Uniform blocks made from 40 pcf density resin were also used to simulate bone areas of greater density.

The advantages of BLTBs, as cited by the ASTM F-1839-08 “Standard Specification for Rigid Polyurethane Foam for Use as a Standard Material for Testing Orthopaedic Devices and Instruments"

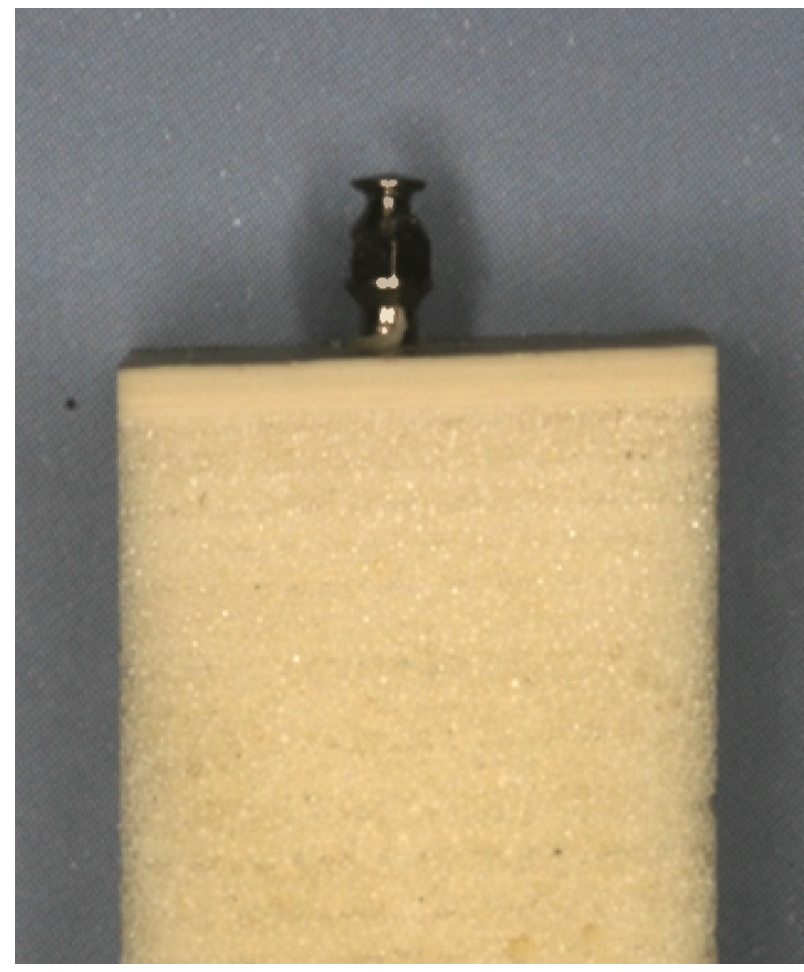

Figure 2. Photograph of an $\mathrm{Ml}$ inserted in synthetic bone block with 1 -mm-thick cortical bone layer.

are as follows: 1) a more reliable test bed than natural or cadaveric specimens; 2) lower variability in testing for all insertion implant samples, because all blocks have the same density and mechanical properties; and 3) easier special handling and no preservation requirements. Natural bone varies in density, stiffness, and mechanical resistance, which makes it more difficult to analyze the influence of a single parameter. The objective of the present work was to analyze the influence of cortical thickness only, and it was therefore very important to reduce the number of variable parameters during mechanical testing.

Pilot drilling was performed prior to the insertion of MI using a 1.0-mm-diameter drill. A system comprising two mandrels compressed with an elastic ribbon to induce a compression force of $4 \mathrm{~N}$ from $\mathrm{MI}$ against the synthetic bone blocks was used in the insertion torque test of MIs (Figure 3).

Mechanical testing of the samples was performed with an EMIC DL 10.000 universal testing machine (EMIC Equipamentos e Sistemas de Ensaio Ltda., 


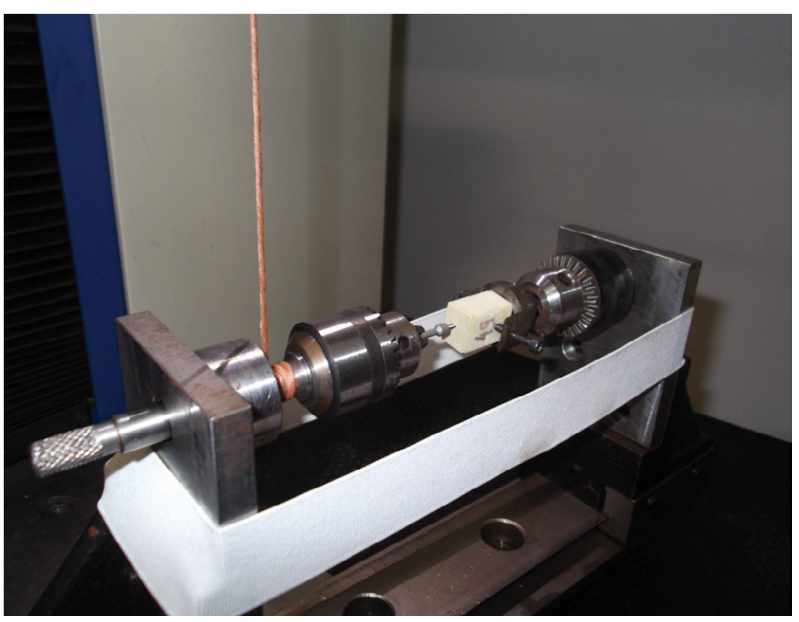

Figure 3. Photograph of the device used in the torsion mechanical testing of Mls.

São José dos Pinhais, Brazil), with a $500 \mathrm{~N}$ load cell and a displacement of $1 \mathrm{~cm} / \mathrm{min}$. Insertion torque variance was obtained graphically. Primary stability was considered as the maximum insertion torque. The mechanical device has an accuracy of 2.0 gf.cm (0.02 N.cm).

Data from all groups were analyzed using SPSS for Windows, version 17.0 (IBM SPSS Inc., Chicago, USA). Mean, standard deviation, and maximum and minimum values were calculated. The normality of the data was checked by the Kolmogorov-Smirnov test. Results were analyzed by one-way ANOVA and Tukey's post hoc test to detect differences among the groups. A $p$-value $<0.05$ was accepted as statistically significant.

\section{Results}

Insertion torque increased with increasing cortical bone thickness when either MI was used. For the same MI length, significant differences were observed among all groups assessed. Insertion torque values of the 6-mm-long MI inserted in a 3-mm-thick cortical bone were equivalent to the insertion torque values of the 8-mm-long MI inserted in a 1-mm-thick cortical bone (Table 1).

Figure 4 shows the variance in insertion torque values for both MI sizes when inserted in different cortical bone thicknesses. The increase in stability from cortical bone thickness $1 \mathrm{~mm}$ to $2 \mathrm{~mm}$ was greater than the increase from thickness $2 \mathrm{~mm}$ to $3 \mathrm{~mm}$.

\section{Discussion}

Cortical bone thickness and density, as well as adequate insertion torque, are important factors to be considered when MIs are inserted, both for primary stability and for fracture risk during installation. The insertion torque results obtained in the present study suggest that the different lengths of MI are dependent on cortical bone thickness.

Cortical bone thickness varies from 0.5 to $2.5 \mathrm{~mm}$ in the vestibular alveolar process $\mathrm{s}^{5,12,13,21}$, and from 1.0 to $1.5 \mathrm{~mm}$ in the palatal alveolar process. ${ }^{22}$ Therefore, cortical thicknesses from 1 to $3 \mathrm{~mm}$ were selected to test the insertion torque of MI because cortical bone thickness is directly related to insertion torque, and insertion torque influences MI success rates. ${ }^{23}$ Uniform blocks made of 40 pcf density resin were used to simulate bone areas of the palate, where, in some sites, the whole bone

Table 1. Mean, standard deviation and variance of insertion torque values of $6 \mathrm{~mm}$ - and $8 \mathrm{~mm}$-long mini-implants (N.cm) in the different cortical bone thicknesses tested and statistically significant differences among the groups according to the Tukey's post hoc test.

\begin{tabular}{ccccc}
\hline & Cortical Bone Thickness & Mean (SD) & Variance & Statistically Significant Difference* \\
\hline $6 \mathrm{~mm}$-long MI & $1 \mathrm{~mm}$ & $7.60(0.13)$ & $7.32-8.09$ & $\mathrm{~A}$ \\
& $2 \mathrm{~mm}$ & $13.27(0.34)$ & $12.30-13.89$ & $\mathrm{~B}$ \\
& $3 \mathrm{~mm}$ & $16.11(0.23)$ & $15.52-16.61$ & $\mathrm{C}$ \\
$8 \mathrm{~mm}$-long MI & Denser bone & $23.95(0.11)$ & $23.50-24.11$ & $\mathrm{D}$ \\
& $1 \mathrm{~mm}$ & $15.66(0.33)$ & $14.42-16.42$ & $\mathrm{C}$ \\
& $2 \mathrm{~mm}$ & $24.13(0.52)$ & $22.15-25.15$ & $\mathrm{D}$ \\
& $3 \mathrm{~mm}$ & $27.36(0.60)$ & $25.65-28.72$ & $\mathrm{E}$ \\
\end{tabular}

*Different letters mean statistically significant differences $(p<0.05)$ 


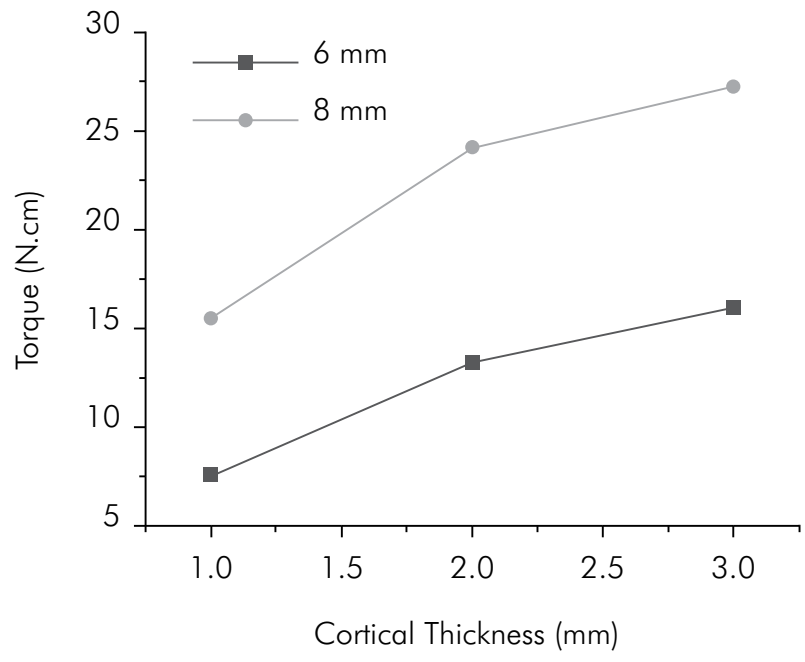

Figure 4. Variance in insertion torque values for 6 - and 8-mm Mls inserted in cortical bone of different thicknesses.

thickness can be less than the length of the 6-mm-long MI, according to Baumgaertel. ${ }^{22}$

The 6- and 8-mm-long MIs were used in the present study because they are the sizes most often used clinically. ${ }^{1}$

Bone anatomy is subject to considerable individual variation in terms of cortical bone thickness, which can be relatively well assessed by computed tomography. ${ }^{22}$ However, this is not a routine examination in orthodontic clinics. Therefore, as previous studies have mapped and proposed mean values of cortical bone thickness for different sites of MI' implantation, ${ }^{21,22}$ it would be useful to use them as a reference when selecting an MI', particularly because differences in the primary stability of MIs were not observed to be associated with cortical bone density. ${ }^{14}$ The adequate length of MI to be inserted may be selected on the basis of cortical bone thickness values proposed in the literature ${ }^{18}$ and by the insertion torque values measured in this study. In addition, procedures that minimize the insertion torque value, such as cortical bone pilot drilling, may also be used. Shorter MIs have a lower fracture risk in thicker cortical bone and in denser bone.

Various sites are used to insert MIs, but the most common are the palatine raphe, the region distal to the last molar and edentulous areas, and particularly the spaces between the roots of adjacent teeth.
The insertion torque values observed in this study when the 8-mm-long MI was used in the denser bone and in cortical bone thicknesses of 2 and $3 \mathrm{~mm}$ were close to the fracture torque values reported in some other studies. ${ }^{6,24,25,26,27}$ Therefore, the length of MI combined with the $1.5 \mathrm{~mm}$ diameter tested would not be recommended for insertion in the median and posterior regions of the mandible and in the palate but for the maxillary interroot spaces in all vestibular alveolar processes. The 6-mm-long MI had a very low insertion torque value when used in 1-mm-thick cortical bone. Consequently, its use should be recommended in sites previously cited as contraindicated for the $8 \mathrm{~mm}$ MI, and in the higher region of the palate (Figure 4) it should preferably be preceded by pilot drilling.

MIs inserted in synthetic bone blocks of greater density had primary stability values almost twice as high as those in other groups. These values were above those recommended in the literature. The ideal insertion torque for MIs designed for orthodontic anchorage vary from 5 to $10 \mathrm{~N}$.cm for different cortical bone thicknesses. ${ }^{23}$ The presence of microthreads (Figure 1A) with smaller thread pitch increases the number or threads per length unit and increases the contact area of MI with the bone. This change in MI design will increase primary stability measured by the insertion torque. In addition to this characteristic, MIs tested present a flat surface on the upper microthreads and an angulated surface on the lower threads (Figure 1B). This shape compacts the bone during insertion and tends to increase primary stability.

The anatomic location of MI is among the risk factors related to stability; therefore, the use of MIs of different lengths at different insertion sites is suggested in Table 2. This proposal is compatible with the different bone densities reported in previous studies for different sites in humans. ${ }^{16,28}$ Nevertheless,

Table 2. Indication of $\mathrm{Ml}^{\prime}$ length to be used in different sites in the maxilla and mandible, based on the cortical bone thickness.

\begin{tabular}{lll}
\hline \multicolumn{1}{c}{ Mandible } & \multicolumn{1}{c}{ Maxilla } \\
\hline $6 \mathrm{~mm}$ & $\begin{array}{l}\text { interroot spaces in the } \\
\text { median and posterior } \\
\text { areas, retromolar area }\end{array}$ & palate, edentulous areas \\
$8 \mathrm{~mm}$ & $\begin{array}{l}\text { interroot spaces in the } \\
\text { anterior area }\end{array}$ & $\begin{array}{l}\text { interroot spaces in all } \\
\text { vestibular alveolar process }\end{array}$ \\
\hline
\end{tabular}


studies must be performed to relate the use of different lengths of $\mathrm{MI}$ in the recommended sites, providing the corresponding success rates.

The distribution of the data points in Figure 4 shows that they are not represented by a straight line, indicating that insertion torque does not vary linearly with increasing cortical bone thickness. By adjusting the curve to an exponential form, the following equation was obtained: $\mathrm{T}=\mathrm{B} \cdot \mathrm{Th}^{\mathrm{m}}$, where $\mathrm{T}$ is insertion torque, $\mathrm{Th}$ is cortical bone thickness, and $\mathrm{B}$ and $\mathrm{m}$ are parameters that depend on implant shape, insertion material, and the friction coefficient between implant and bone. After substitution and calculation, torque variation is related to cortical bone thickness according to the following relationships: $\mathrm{T}=7.6 \mathrm{Th}^{0.667}$ for the 6-mm-long $\mathrm{MI}$, and $\mathrm{T}=15.66 \mathrm{Th}^{0.520}$ for the 8-mm-long MI.

The differences in parameters B and $\mathrm{m}$ for Mls of 6 and $8 \mathrm{~mm}$ length arises because they have different friction force during insertion. This can be explained on the basis of the study by Elias et al., ${ }^{29}$ who analyzed the effects of shape, surface morphology, surgical technique, and bone quality on the primary stability of dental implants. They observed that the friction force (Ff) at any point on the thread during implant insertion is given by the equation $\mathrm{F}_{\mathrm{f}}=\mathrm{u} . \mathrm{N}$, where $\mathrm{u}$ is the friction coefficient and $\mathrm{N}$ is the force acting on the screw in the plane normal to the surface of the screw thread. The friction coefficient is a function of screw shape, thread geometry, placement material properties, and site diameter. The relationship between the friction force and insertion torque (Tf) is

\section{References}

1. Chen $\mathrm{CH}$, Chang CS, Hsieh CH, Tseng YC, Shen YS, Huang IY, et al. The use of microimplants in orthodontic anchorage. J Oral Maxillofac Surg. 2006 Aug;64(8):1209-13.

2. Alves-Jr M, Baratieri C, Nojima LI. Assessment of mini-implant displacement using cone beam computed tomography. Clin Oral Implants Res. 2011 Oct;22(10):1151-6.

3. Liou EJ, Pai BC, Lin JC. Do miniscrews remain stationary under orthodontic forces?. Am J Orthod Dentofacial Orthop. 2004 Jul;126(1):42-7.

4. Costa A, Raffainl M, Melsen B. Miniscrews as orthodontic anchorage: a preliminary report. Int J Adult Orthodon Orthognath Surg. 1998;13(3):201-9.

5. Motoyoshi M, Inaba M, Ono A, Ueno S, Shimizu N. The effect of cortical bone thickness on the stability of orthodontic
$\mathrm{Tf}=$ Ff.r, where $\mathrm{r}$ is implant diameter. In order to insert the implant, the force and torque applied by the surgeon must be larger than the friction force. ${ }^{29}$

The use of the proposed equation allows interpolation and extrapolation of values to obtain possible insertion torques for different cortical bone thicknesses. This equation may aid professionals in estimating primary stability in different surgical conditions. One limitation of this study is that translation of these results into clinical considerations may be questionable because polyurethane blocks were used. However, the homogeneity of the synthetic bone allowed standardization and comparison among the different situations that were tested.

With the results of the present study, the installation of MIs becomes more secure because the insertion torque obtained was less than the maximum insertion torque required to fracture the anchorage devices. In addition, it is possible to determine adequate MI lengths to avoid fracture of MI.

\section{Conclusion}

Based on the results of this study, we conclude that 1) shorter MIs have lower primary stability as measured by insertion torque, and 2) the greater the cortical bone thickness, the greater the primary stability. In addition, to minimize fracture risk, it is proposed that of the MI size should be selected according to the insertion site, using a mathematical equation to predict insertion torque.

mini-implants and on the stress distribution in surrounding bone. Int J Oral Maxillofac Surg. 2009 Jan;38(1):13-8.

6. Lima GM, Soares MS, Penha SS, Romano MM. Comparison of the fracture torque of different Brazilian mini-implants. Braz Oral Res. 2011 Mar-Apr;25(2):116-21.

7. Kravitz ND, Kusnoto B. Risks and complications of orthodontic miniscrews. Am J Orthod Dentofacial Orthop. 2007 Apr;131(4 Suppl):S43-51.

8. Miyawaki S, Koyama I, Inoue M, Mishima K, Sugahara T, Takano-Yamamoto T. Factors associated with the stability of titanium screws placed in the posterior region for orthodontic anchorage. Am J Orthod Dentofacial Orthop. 2003 Oct;124(4):373-8. 
9. Reynders R, Ronchi L, Bipat S. Mini-implants in orthodontics: a systematic review of the literature. Am J Orthod Dentofacial Orthop 2009 May;135(5):564.e1-564.e19.

10. Meursinge Reynders R, Ronchi L, Ladu L, van Etten-Jamaludin F, Bipat S. Insertion torque and success of orthodontic mini-implants: a systematic review. Am J Orthod Dentofacial Orthop. 2012 Nov;142(5):596-614.

11. Rodriguez JC, Suarez F, Chan HL, Padial-Molina M, Wang HL. Implants for orthodontic anchorage: success rates and reasons of failures. Implant Dent. 2014 Apr;23(2):155-61.

12. Kim HJ, Yun HS, Park HD, Kim DH, Park YC. Soft-tissue and cortical-bone thickness at orthodontic implant sites. Am J Orthod Dentofacial Orthop. 2006 Aug;130(2):177-82.

13. Lim JE, Lee SJ, Kim YJ, Lim WH, Chun YS. Comparison of cortical bone thickness and root proximity at maxillary and mandibular interradicular sites for orthodontic mini-implant placement. Orthod Craniofac Res. 2009 Nov;12(4):299-304.

14. Marquezan M, Souza MM, Araujo MT, Nojima LI, Nojima MC. Is miniscrew primary stability influenced by bone density? Braz Oral Res. 2011 Sep-Oct;25(5):427-32.

15. Laursen MG, Melsen B, Cattaneo PM. An evaluation of insertion sites for mini-implants. a micro-CT study of human autopsy material. Angle Orthod. 2013 Mar;83(2):222-9.

16. Misch CE, Qu Z, Bidez MW. Mechanical properties of trabecular bone in the human mandible: implications for dental implant treatment planning and surgical placement. J Oral Maxillofac Surg. 1999 Jun;57(6):700-6; discussion 706-8.

17. Lin T, Tsai FD, Chen CY, Lin LW. Factorial analysis of variables affecting bone stress adjacent to the orthodontic anchorage mini-implant with finite element analysis. Am J Orthod Dentofacial Orthop. 2013 Feb;143(2):182-9.

18. Pithon MM, Figueiredo DSF, Oliveira DD. Mechanical evaluation of orthodontic mini-implants of different lengths. J Oral Maxillofac Surg. 2013 Mar;71(3):479-86.

19. Kwon Y, Namgoong H, Kim JH, Cho IH, Kim MD, Eom TG, et al. Effect of microthreads on removal torque and bone-to- implant contact: an experimental study in miniature pigs. J Periodontal Implant Sci. 2013 Feb;43(1):41-6.

20. Chang JZ, Chen YJ, Tung YY, Chiang YY, Lai EH, Chen WP, et al. Effects of thread depth, taper shape, and taper length on the mechanical properties of mini-implants. Am J Orthod Dentofacial Orthop. 2012 Mar;141(3):279-88.

21. Baumgaertel S, Hans MG. Buccal cortical bone thickness for mini-implant placement. Am J Orthod Dentofacial Orthop. 2009 Aug;136(2):230-5.

22. BaumgaertelS. Quantitative investigation of palatal bone depth and cortical bone thickness for mini-implant placement in adults. Am J Orthod Dentofacial Orthop. 2009 Jul;136(1):104-8.

23. Motoyoshi M, Hirabayashi M, Uemura M, Shimizu N. Recommended placement torque when tightening an orthodontic mini-implant. Clin Oral Implants Res. 2006 Feb;17(1):109-14.

24. Mattos CT, Ruellas ACO, Elias CN. Is it possible to re-use mini-implants for orthodontic anchorage? Results of an in vitro study. Mat Res. 2010 Oct-Dec;13(4):521-5.

25. Mattos CT, Ruellas AC, Sant'anna EF. Effect of autoclaving on the fracture torque of mini-implants used for orthodontic anchorage. J Orthod. 2011 Mar;38(1):15-20.

26. Ruellas ACO, Mattos CT, Elias CN. Avaliação dos torques de inserção e remoção e da resistência mecânica de novos mini-implantes ortodônticos. Orthod Sci Practice. 2012;17(5):23-27.

27. Pithon M, Nojima L, Nojima MC, Ruellas AC. Comparative study of fracture torque for orthodontic mini-implants of different trademarks. Oral Surg. 2008 May;1(2):84-7.

28. Chun YS, Lim WH. Bone density at interradicular sites: implications for orthodontic mini-implant placement. Orthod Craniofac Res. 2009 Feb;12(1):25-32.

29. Elias CN, Rocha FA, Nascimento AL, Coelho PG. Influence of implant shape, surface morphology, surgical technique and bone quality on the primary stability of dental implants. J Mech Behav Biomed Mater. 2012 Dec;16:169-80. 